\title{
O DIREITO HUMANO À ÁGUA POTÁVEL: PROTEÇÃO JURÍDICA, EDUCAÇÃO, CONSCIENTIZAÇÃO E ATITUDES AMBIENTAIS
}

\section{Deise Marcelino Silva ${ }^{1}$}

\section{Zulmar Fachin ${ }^{2}$}

RESUMO: O trabalho objetiva identificar a proteção que o ordenamento jurídico brasileiro oferece à água potável, mas sustenta a necessidade de ir além do Direito, propugnando por um caminho mais amplo e eficaz a exigir educação, conscientização e atitude ambientais. Reconhece que a escassez de água potável é um fato incontestável e, embora reconhecendo a imprescindibilidade do Direito, propõe alternativas que vão além da proteção jurídica existente. Educação, conscientização e atitude ambientais devem estar aliadas ao Direito. O homem é um ser individual e social capaz de reverter o cenário de crise ambiental que a era moderna desencadeou e que a pós-modernidade alimenta. Estudiosos de diversas áreas do conhecimento apontam a educação ambiental como uma das principais formas para superar os problemas ambientais vigentes $^{3}$, uma vez que ela se reveste de ações e práticas voltadas à formação de uma consciência ambiental que possibilite aos vários atores sociais compreenderem e participarem ativamente na transformação da realidade.

\footnotetext{
1 Mestre em Direito da Personalidade pelo Centro Universitário de Maringá/PR. Pós graduanda em Docência no Ensino Superior. Professora. deise.marcelino@hotmail.com ${ }^{2}$ Doutor em Direito Constitucional (UFPR). Professor de Direito constitucional na Graduação e no Mestrado. Membro da Comissão Nacional de Estudos Constitucionais do Conselho Federal da OAB. Presidente do IDCC, Londrina/PR. zulmarfachin@uol.com.br

${ }^{3}$ Cf. Celso Antonio Pacheco Fiorillo, Curso de direito ambiental brasileiro. São Paulo: Saraiva, 2009 , p. 58
} 
Palavras-chave: Água potável. Educação ambiental. Conscientização ambiental.

\section{INTRODUÇÃO}

Em 24 de julho de 1934, foi editado pelo Governo Provisório de Getúlio Vargas o Decreto n. 24.642, instituindo o Código de Águas. Trata-se do documento jurídico-normativo mais antigo, editado no Brasil, com o objetivo específico de proteger as águas. Referido decreto, mas tarde, foi modificado pelo Decreto-lei n. 852, de 11 de novembro de 1938. Já o Decreto-lei n. 2.676, de 4 de outubro de 1940, dispôs sobre a aplicação de penalidades por infração a artigos do Código de Águas. Registre-se, ainda, que, em 25 de outubro de 1941, foi editado o Decreto-lei n. 3.763, com o propósito de consolidar as disposições legais sobre águas e energia elétrica. A Constituição de 1934 previu serem de domínio da União os lagos e quaisquer outras correntes localizadas em terrenos de seu domínio.

Embora a proteção jurídica brasileira sobre água tenha nascido na década de trinta do século passado, pode-se afirmar que a temática não foi tratada num contexto de reais preocupações com o equilíbrio ecológico. Por outro lado, nos dias atuais, o sentimento de incertezas frente às degradações dos recursos naturais, em especial, a água potável, exige que toda a sociedade se mobilize para combater questões ambientais adversas cada vez mais emergentes. Os envolvidos devem lançar mão de instrumentos como a educação e a conscientização ambientais para que, após compreender sua realidade circundante, possam desenvolver atitudes éticas e políticas, mas principalmente, ambientais.

\section{PROTEÇÃO CONSTITUCIONAL}


A Constituição de 1988, ao proteger o meio ambiente como direito fundamental, estabeleceu ampla proteção às águas, colocando-as sob a proteção dos membros do pacto federativo (art. 225). Nesse sentido, pertencem à União o mar territorial (art. 20, inciso VI), os potenciais de energia hidráulica (art. 20, inciso VIII) e "os lagos, rios e qualquer corrente de água em terrenos de seu domínio, ou que banhem mais de um Estado, sirvam de limites com outros países, ou se estendam a território estrangeiro ou dele provenham, bem como os terrenos marginais e as praias fluviais" (art. 20, inciso III).

Por outro lado, ficou assegurado que pertencem aos Estados as ilhas fluviais e lacustres não pertencentes à União (art. 26, incisos I e II) e as águas superficiais ou subterrâneas, fluentes, emergentes e em depósito, salvo, quanto a estas, se decorrerem de obras da União (art. 26, inciso I). No que tange à competência material, cabe à União instituir sistema nacional de gerenciamento de recursos hídricos e definir critérios de outorga de direitos de uso, bem como instituir diretrizes para o desenvolvimento urbano, inclusive habitação, saneamento básico e transportes urbanos (art. 21, incisos XIX e $X X)$. À União compete também legislar privativamente sobre águas e energia (art. 22, incisos IV).

Registre-se que a Constituição estabeleceu competência material comum (União, Estados, Distrito Federal e Municípios) para proteger o meio ambiente (art. 23, inciso VI) e competência concorrente (União, Estados e Distrito Federal) para legislar sobre conservação da natureza, defesa dos recursos naturais, proteção do meio ambiente e controle de poluição (art. 24, inciso VI), bem como sobre a responsabilidade civil por dano ao meio ambiente (art. 24, inciso VIII).

A Constituição assegurou, ainda, meios processuais que podem ser utilizados para proteção judicial das águas, tais como a ação popular (art. 5o inciso LXXIII), a ação civil pública (art. 129, inciso III), o mandado de segurança 


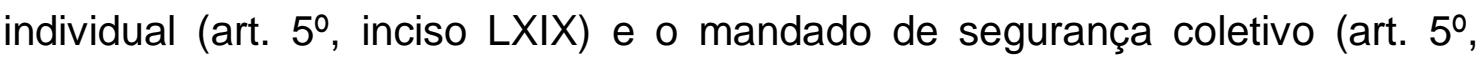
inciso $L X X)^{4}$.

\section{LEI DAS ÁGUAS}

A Lei n. 9.433, publicada em 8 de janeiro de 1997, instituiu a Política Nacional de Recursos Hídricos, criou o Sistema Nacional de Gerenciamento de Recursos Hídricos, regulamentou a norma do art. 21, inciso XIX, da Constituição Federal e alterou dispositivo legal.

A Política Nacional de Recursos Hídricos foi elaborada com base nos seguintes fundamentos: a) a água é um bem de domínio público; b) a água é um recurso natural limitado, dotado de valor econômico; c) em situações de escassez, o uso prioritário dos recursos hídricos é o consumo humano e a dessedentação de animais; d) a gestão dos recursos hídricos deve sempre proporcionar o uso múltiplo das águas; e) a bacia hidrográfica é a unidade territorial para implementação da Política Nacional de Recursos Hídricos e atuação do Sistema Nacional de Gerenciamento de Recursos Hídricos; f) a gestão dos recursos hídricos deve ser descentralizada e contar com a participação do Poder Público, dos usuários e das comunidades (art. 1ํ).

Os objetivos da Política Nacional de Recursos Hídricos são: a) assegurar à atual e às futuras gerações a necessária disponibilidade de água, em padrões de qualidade adequados aos respectivos usos; b) a utilização racional e integrada dos recursos hídricos, incluindo o transporte aquaviário, com vistas ao desenvolvimento sustentável; c) a prevenção e a defesa contra eventos hidrológicos críticos de origem natural ou decorrentes do uso inadequado dos recursos naturais (art. $2^{\circ}$ ).

As diretrizes gerais da Política Nacional de Recursos Hídricos: a) a gestão sistemática dos recursos hídricos, sem dissociação dos aspectos de

\footnotetext{
${ }^{4}$ FACHIN, Zulmar. Curso de Direito Constitucional. 3. ed. São Paulo: Método, 2008, p. 304 e
} 322. 
quantidade e qualidade; b) a adequação da gestão de recursos hídricos às diversidades físicas, bióticas, demográficas, econômicas, sociais e culturais das diversas regiões do País; c) a integração da gestão de recursos hídricos com a gestão ambiental; d) a articulação do planejamento de recursos hídricos com o dos setores usuários e com os planejamentos regional, estadual e nacional; e) a articulação da gestão de recursos hídricos com a do uso do solo; f) a integração da gestão das bacias hidrográficas com a dos sistemas estuarinos e zonas costeiras (art. $3^{\circ}$ ).

A Lei n. 9.433, de 08 de janeiro de 2007, elegeu os instrumentos da Política Nacional de Recursos Hídricos: a) os Planos de Recursos Hídricos; b) o enquadramento dos corpos de água em classes, segundo os usos preponderantes da água; c) a outorga dos direitos de uso de recursos hídricos; d) a cobrança pelo uso de recursos hídricos; e) a compensação a municípios vetado; f) o Sistema de Informações sobre Recursos Hídricos (art. 5.).

A Lei n. 9.433, de 8 de janeiro de 1997, atribuiu ao Sistema Nacional de Gerenciamento de Recursos Hídricos competência para: a) promover a articulação do planejamento de recursos hídricos com os planejamentos nacional, regional, estaduais e dos setores usuários; b) arbitrar, em última instância administrativa, os conflitos existentes entre Conselhos Estaduais de Recursos Hídricos; c) deliberar sobre os projetos de aproveitamento de recursos hídricos cujas repercussões extrapolem o âmbito dos Estados em que serão implantados; d) deliberar sobre as questões que the tenham sido encaminhadas pelos Conselhos Estaduais de Recursos Hídricos ou pelos Comitês de Bacia Hidrográfica; e) analisar propostas de alteração da legislação pertinente a recursos hídricos e à Política Nacional de Recursos Hídricos; f) estabelecer diretrizes complementares para implementação da Política Nacional de Recursos Hídricos, aplicação de seus instrumentos e atuação do Sistema Nacional de Gerenciamento de Recursos Hídricos; g) aprovar propostas de instituição dos Comitês de Bacia Hidrográfica e estabelecer critérios gerais para a elaboração de seus regimentos; h) acompanhar a 
execução e aprovar o Plano Nacional de Recursos Hídricos e determinar as providências necessárias ao cumprimento de suas metas; i) estabelecer critérios gerais para a outorga de direitos de uso de recursos hídricos e para a cobrança por seu uso (art. 35).

\section{EDUCAÇÃO AMBIENTAL}

A expressão educação ambiental foi oficialmente adotada no âmbito dos encontros internacionais sobre ambiente humano. No entanto, foi na Conferência de Educação, realizada na Grã-Bretanha, em 1965, que a terminologia educação ambiental (Environmental Education) foi usada e passou a fazer parte das diretrizes educacionais.

A segunda metade do século $X X$ deu início às conferências internacionais sobre meio ambiente, baseando-se em preocupações ocasionadas pelo modelo de desenvolvimento adotado pelos países ocidentais. Acredita-se que foi em decorrência da grande catástrofe ambiental, ocorrida em Londres, em 1952 - devido à densa poluição no ar - que a temática ambiental começou a ser discutida e inserida no meio acadêmico, embora de maneira tímida e vinculada à ecologia aplicada ${ }^{5}$.

O desenvolvimento da política social de proteção ambiental no âmbito internacional continuou a ser tema de outras reuniões, mas foi na Conferência Intergovernamental de Tbilisi, de 1977, promovida pela UNESCO, que se falou em educação ambiental de modo mais específico. Os objetivos do encontro eram, dentre outros, projetar a educação ambiental sob aspecto global, permitir sua base interdisciplinar, demonstrar a interdependência entre as comunidades e fomentar a solidariedade entre os povos ${ }^{6}$.

\footnotetext{
${ }^{5}$ DIAS, Genebaldo Freire. Educação ambiental: princípios e práticas. 8 ed, São Paulo: Gaia, 2003. p.77.

${ }^{6}$ DIAS, Genebaldo Freire. Educação ambiental: princípios e práticas. 8 ed, São Paulo: Gaia, 2003. p. $104 / 105$.
} 
Os valores da educação ambiental adotados no Brasil têm origem na ideologia dos encontros internacionais, registrando a integração do Brasil no cenário externo.

Em consonância com o cenário internacional, o Brasil foi sede, em 1992, da Conferência das Nações Unidas sobre Meio Ambiente e Desenvolvimento (Rio-92), da qual participaram mais de 180 países. A Jornada Internacional de Educação Ambiental, realizada no Fórum Global da Eco 92, reafirma o compromisso crítico da Educação Ambiental, expresso no "Tratado de Educação Ambiental para as Sociedades Sustentáveis e Responsabilidade Global". O Tratado diz que a educação ambiental não é neutra, mas ideológica; é um ato político baseado em valores para a transformação social. O Tratado considera a educação ambiental para a sustentabilidade eqüitativa como "um processo de aprendizagem permanente, baseado no respeito a todas as formas de vida". Tal processo afirma valores e ações que contribuem para a transformação humana e social e para a preservação ecológica ${ }^{7}$.

Ao se voltar para os cuidados com a sustentabilidade hídrica, a Carta de Montreal sobre Água Potável e Saneamento, publicada em 1990, afirma que a administração dirigida apenas para os trabalhos estritamente técnicos não é satisfatória nem suficiente, sendo a educação uma forma de estimular a participação social nas matérias pertinentes à água ${ }^{8}$.

Foi, portanto nesse contexto, que o Brasil publicou a Política Nacional de Educação Ambiental.

A questão ambiental brasileira recebeu tratamento normativo específico na década de 80, com a promulgação da Lei ํo. 6.983, de 31 de agosto de 1981, que institui a Política Nacional do Meio Ambiente. Esta lei concebeu a educação ambiental como um instrumento estratégico que garantirá a postura de consciência ante os problemas ecos-sociais, na

\footnotetext{
${ }^{7}$ ANA, Conselho Nacional de Desenvolvimento Científico e Tecnológico. Educação Ambiental e Gestão dos Recursos Hídricos. UEM. 2008. p.25.

${ }^{8}$ COMMETTI, F.D. et.al. O desenvolvimento do direito das águas como um ramo autônomo da ciência jurídica brasileiro. Revista de direito ambiental. 2008. p. 67.
} 
perspectiva da construção de um saber ambiental. Este regulamento serve como instrumento orientador para as perspectivas dos órgãos da administração pública para compatibilizar o desenvolvimento socioeconômico com a manutenção da qualidade e equilíbrio ecológico.

Também nesta mesma década, foi promulgada a Constituição Brasileira de 1988 que, comprometida com a cidadania ambiental, elegeu a educação como princípio inspirador das atividades do poder público e dos particulares. O artigo 255, $\S 1^{\circ}$, inciso VI, determina ao Poder Público, a promoção da educação ambiental em todos os seus níveis de ensino, e conclama uma conscientização pública para a preservação do meio ambiente.

Esse dispositivo constitucional exige do poder público 0 desenvolvimento de uma consciência focada na sustentabilidade socioambiental. No entanto, para sua aplicabilidade, é necessário conclamar as comunidades ao exercício cooperativo. Geralmente, na prática, a participação social se dá por meio das instituições por ocasião da liberação de recursos para o desenvolvimento de planos, programas e projetos, tanto de nível local quanto regional (estadual) e nacional. Sendo assim, para liberar recursos, exigem-se instituições fortalecidas e normas previamente estabelecidas. Neste contexto, o artigo 255, em sua parte que estipula sobre a promoção da educação ambiental, foi regulamentado pela Lei 9.795, de 27 de abril de 1999, que dispõe sobre a Educação Ambiental e institui a Política Nacional de Educação Ambiental.

A Lei de Educação Ambiental brasileira é composta de 21 artigos com quatro capítulos e três seções. O primeiro capítulo trata da Educação Ambiental em termos de conceito; processo de educação; das instituições educacionais; componentes do Sistema de Gestão Ambiental; e dos meios de comunicação e a sociedade civil. Compõem também este capítulo os princípios e os fundamentos para a gestão proposta. O segundo capítulo trata da Política Nacional de Educação Ambiental: Seção I - Disposições Gerais; Seção II - Da Educação Ambiental no Ensino Formal; Seção III - Da Educação Ambiental não 
Formal. O terceiro capítulo trata da Execução da Política Nacional de Educação Ambiental, e o quarto e último capítulo, trata das Disposições finais.

Tais princípios se encontram aplicados a passos que dependem do consciente individual reforçado pelo consciente coletivo. Vale lembrar que 0 consciente é, geralmente, cultural e determinado por correntes de interesses, tanto pessoal como social. Desta forma, a construção dos valores para a manutenção dos fatores ambientais depende do que há para a troca, do que pode ser negociado. Se a natureza sempre foi conceituada como a mãe natureza, aquela que tudo concede, não havia com o que se preocupar.

Visando reverter essa cultura, é auspicioso tomar como pilar o princípio que determina ser necessário "a concepção do meio ambiente em sua totalidade, considerando a interdependência entre o meio natural, o sócioeconômico e o cultural, sob o enfoque da sustentabilidade" (art. $4^{\circ}$, II da Lei 9795/99). Assim como é urgente se lançar mão de outro princípio, o qual sugere "o pluralismo de idéias e concepções pedagógicas, na perspectiva da inter, multi e transdisciplinaridade" (art. $4^{\circ}$, III), como propulsores da construção de novos paradigmas, em termos de valores de conservação e preservação ambiental.

Por outro lado, a referida Lei estabelece que as atividades vinculadas à Política Nacional de Educação Ambiental devem ser desenvolvidas na educação em geral e na educação escolar, por meio de atuações interrelacionadas, tais como: "I - capacitação de recursos humanos; II desenvolvimento de estudos, pesquisas e experimentações; III - produção e divulgação de material educativo; IV - acompanhamento e avaliação" (art. 8).

Os fundamentos e as linhas de atuação expostos na lei corroboram no sentido de se manter os princípios da educação ambiental. A política instituída pela Lei é democrática, de cunho participativa e de visão holística, pois contempla valores políticos, sociais, étnicos, culturais e econômicos. Este último fator distanciou o homem da sua condição de partícula componente do sistema ambiental. No entanto, a aplicabilidade dos mecanismos que a Política 
propõe, visa resgatar o homem a refletir sua condição de integrante de um sistema no qual todos se complementam e tudo interage com tudo. Essa visão holística só pode ser entendida com a educação, meio de difusão dos conhecimentos culturais, e em específico, conhecimentos eco-ambientais.

Registre-se que a Lei de Educação Ambiental destaca que a educação ambiental deve estar prevista nos currículos tanto nas escolas públicas quanto nas particulares, de modo a abranger: "I - educação básica: a) educação infantil; b) ensino fundamental e c) ensino médio; II - educação superior; III educação especial; IV - educação profissional; V - educação de jovens e adultos" (art. 9.).

Nesse sentido, as escolas públicas e as escolas particulares devem seguir a orientação legal para a aplicação da educação ambiental no âmbito de sua grade curricular. Por conseguinte, os conteúdos curriculares devem abordar a educação ambiental como tema transversal, envolvendo vasto número das disciplinas. Outrossim, deve-se levar em consideração que nenhuma disciplina, isoladamente, pode abarcar os muitos assuntos relativos às funções ecológicas e do ambiente sociocultural.

Registre-se que, neste tema, não só apenas as instituições estatais têm responsabilidade. A sociedade também tem papel fundamental na efetivação da educação ambiental, e não pode se eximir da responsabilidade de contribuir para a aplicabilidade das propostas previstas na lei sobre tal educação. Nota-se, então, que foi concebido um modelo de educação ambiental que vai além dos limites das instituições estatais, concebendo-se uma visão holística em relação a todos os fenômenos da natureza.

Por outro lado, a Lei de Educação Ambiental determina que, em seus respectivos âmbitos de atuação, "Os Estados, Distrito Federal e Municípios, na esfera de sua competência e áreas de sua jurisdição, devem definir diretrizes, normas e critérios para a educação ambiental dentro das diretrizes da Política Nacional de Educação Ambiental" (art. 16). 
Portanto, estas entidades federativas devem implementar suas políticas de educação ambiental por meio de leis estaduais, distritais e municipais, as quais devem definir programas capazes de proteger os recursos hídricos em seus respectivos limites territoriais. Contudo, apenas leis não bastarão. Será necessária a vigilância por parte da sociedade para que, efetivamente, seja possível vivenciar uma educação ambiental pautada na conservação e preservação, nos valores humanos de harmonia entre os povos e com justiça social.

A doutrina tem valorizado a educação como tema central em matéria ambiental. Na lição de Enrique Leff,

O discurso da sustentabilidade se desdobra, portanto num campo de estratégias teóricas e práticas pela apropriação da natureza, colocando a questão do poder e do poder no saber, onde se inscrevem as estratégias do conhecimento e da educação ambiental ${ }^{9}$.

Diante da necessidade de ir além dos textos normativos, a educação ambiental consiste no primeiro passo a ser dado no sentido de adquirir consciência dos problemas ambientais, especificamente o da água potável, e poder agir na proteção desse bem essencial à vida no Planeta.

\section{CONSCIENTIZAÇÃO AMBIENTAL}

O termo conscientização pode ser compreendido como ato humano de manter relações permanentes com o meio em que se vive e, de maneira mais ampla, com o mundo que se habita. Trata-se de um processo de formação da consciência crítica. A palavra consciência, por sua vez, indica a capacidade de a pessoa compreender o mundo que a cerca e de tomar decisões mais corretas e eficazes diante das circunstâncias da vida.

Nas palavras do professor Paulo Freire

\footnotetext{
${ }^{9}$ LEFF, Enrique. Saber ambiental: sustentabilidade, racionalidade, complexidade, poder. trad. Lúcia Mathilde Endlich Orth. Petrópolis, Rio de Janeiro: Vozes, 2001.
} 
O homem não pode participar ativamente na história, na sociedade, na transformação da realidade se não for ajudado a tomar consciência da realidade e da sua própria capacidade para a transformar. [...] Ninguém luta contra forças que não entende, cuja importância não meça, cujas formas e contorno não discirna; [...] isso é verdade se refere às forças da natureza [...] isto também é assim nas forças sociais [...]. A realidade não pode ser modificada se não quando o homem descobre que é modificável e que ele o pode fazer ${ }^{10}$.

O processo de conscientização tem como objetivo resgatar o homem do niilismo existencial, provocado pelo poder de obediência - desenvolvido à época do absolutismo -, mas tão atual e adequado à pós-modernidade ${ }^{11} \mathrm{e}$ mostra-Ihe seu potencial, denotando a descoberta da sua própria consciência crítica.

Paulo Freire ensina ainda que há três tipos de consciência: a crítica, a mágica e a fanática. A primeira resulta da mais nobre relação do homem com o seu entorno, pois permite que as informações sejam captadas e submetidas à análise, em processo sempre dinâmico de investigação. A segunda é a consciência ingênua, embora supere o limite da ignorância, não é vista como ato positivo. A terceira é a consciência de pessoas que conseguem perceber os acontecimentos do dia-a-dia, mas partem da premissa de que são impotentes diante da realidade humana ${ }^{12}$.

A contextualização acima possibilita considerar que o processo de conscientização é caracterizado de acordo com a postura reflexiva do homem diante da realidade posta pela vida social.

Enfim, como parte integrante da conscientização social, surge a conscientização ambiental. Trata-se de um entendimento de mundo voltado às questões ambientais para lidar com problemas referentes à crise dos recursos

\footnotetext{
${ }^{10}$ FREIRE, Paulo. Pedagogia do oprimido. São Paulo: Paz e Terra, 1985. p. 48.

${ }^{11}$ Norberto Bobbio apud ZENNI, Alessandro Severino V. Direito e poder na filosofia pósmoderna. Revista Jurídica Cesumar, v. 5, n. 1, 2005, p.17.

${ }^{12}$ FREIRE, Paulo. Educação como prática da liberdade. Rio de Janeiro: Paz e Terra, 2005. p. 113/114.
} 
naturais e a capacidade de visualizar estratégia para a solução. Esta postura está em consonância com a consciência crítica apontada pelo pedagogo Paulo Freire. É exatamente esta modalidade de conscientização que se deve haver diante dos problemas ambientais, especificamente da água potável.

É neste influxo que a conscientização ambiental, quanto à origem, pode ser abordada sob dois aspectos ou pontos de partida: a) educação formal; b) educação informal. A primeira conscientização é aquela normalmente adquirida pela educação ambiental formal. Nesse sentido, a sala de aula e os livros - difundindo estudos dos cientistas - são causa da criação e do desenvolvimento de conscientização para as questões ambientais, especificamente em relação às notícias mundiais de escassez de água doce.

A segunda consciência ambiental advém de entendimento do mundo não acadêmico, e sim de um conhecimento empírico - sabedoria ambiental (sapiência) - pois não se pode dizer que somente a transmissão da ciência cria consciência. Tal fenômeno, muitas vezes, se constrói pela própria interação que o indivíduo possui com o meio - interações fenotípicas. Nessa perspectiva, basta ser homem para que aconteçam as interações/relações diante das respostas do mundo, independentemente de ser ou não alfabetizado. Trata-se de conscientização individual, que circunda ao redor das ações concretas da vida cotidiana.

Neste sentido, é a lição de Arthur Lyon Dahl:

Por exemplo, o sucesso de métodos de planejamento participativo mostrou que mesmo aldeões rurais iletrados compreendem as complexidades de seu ambiente local e são perfeitamente capazes de registrar as mudanças que nele têm lugar, bem como fazer planos para um uso mais eficaz de recursos ${ }^{13}$.

A conscientização é um passo a ser dado pelos indivíduos num caminhar para compreender a problemática das questões ambientais. Somente após ter adquirido plena consciência dos problemas ambientais, eles poderão agir eficazmente.

${ }^{13}$ DAHL, Arthur Lyon. O princípio ecológico. Ecologia e economia em simbiose. Lisboa: Instituto Piaget. 1996. p. 189. 


\section{ATITUDE AMBIENTAL}

A atitude ambiental se caracteriza por um processo de transição no qual o sujeito converte a educação ambiental em atuações efetivas de gerenciamento dos recursos naturais. Visualiza-se, aqui, um caminho lógico a ser percorrido pela sociedade ou por um indivíduo engajado com os acontecimentos de seu tempo. Tal caminho pode ser assim percorrido: as propostas saem do papel para assumir espaço na mente do ser humano (educação); a apreensão e compreensão da proposta, conhecimento que antes se moldava por letras, agora já é apreendido pelo sujeito (conscientização), em seguida, este conhecimento passa a ser materializado no mundo real sob ações concretas (atitude).

Essa interação positiva capacita o ser humano em estabelecer uma relação com a natureza, fugindo da idéia da crise do vínculo ecológico analisada por François $\mathrm{Ost}^{14}$. O autor identifica a crise ecológica no afastamento do homem em relação à natureza. Esta separação se encontra no mundo das idéias, daí a importância da conduta ambiental para que possa ir além da proteção normativa.

Surge, então, uma pluralidade de atores sociais, atuando de modo consciente na defesa do meio ambiente, especificamente da água potável. Podem ser mencionados setores da sociedade civil organizada, tais como, ONG's, colaboradores, empresas privadas, associações, voluntários, imprensa e igrejas. Registre-se que a Campanha da Fraternidade de 2004, intitulada "Água, Fonte de Vida", já expressava preocupação de garantir acesso de todos à água potável.

A proteção ambiental, especificamente da água potável, não será alcançada apenas com normas jurídicas, educação e conscientização

\footnotetext{
${ }^{14}$ OST, François. A natureza á margem da lei: a ecologia à prova do Direito. Lisboa: Instituto Piaget, 1995, p. 9.
} 
ambiental. Contudo, é imprescindível que seja acrescentada atitude ambiental. Em grande medida, a proteção efetiva desse direito fundamental terá que ser realizada, com o labor cotidiano, nas arenas política e social. Nesse sentido, a lição de Norberto Bobbio ${ }^{15}$, proferida em 1964, ao construir os fundamentos dos direitos humanos, permanece revestida de atualidade: "O problema fundamental em relação aos direitos do homem, hoje, não é tanto o de justificálos, mas o de protegê-los. Trata-se de um problema não filosófico, mas político".

Em síntese, educação, consciência e atitude ambientais, especialmente na proteção da água potável, exigem de cada pessoa um compromisso com a resolução desse problema, considerado um dos mais graves do tempo atual. Se o quadro se apresenta grave, exige atitudes de todos, seja em ações isoladas, ou de pequenos grupos, seja em parceria público/privada, ou de uma única instituição. Deve-se destacar que as atitudes ambientais podem acontecer tanto em plano de independência financeira ações simples e corriqueiras de indivíduos -, quanto em situações nas quais se exigem recursos financeiros de grande monta.

Esta última se reveste de garantias financeiras para saírem do papel. Em outras palavras, deve haver o emprego de valores significativos para que projetos ambientais se transformem em ações aplicáveis. Embora os recursos financeiros sejam imprescindíveis para a concretização dos projetos ambientais sobre água potável, eles não acontecem sem as articulações e ações participativas das várias esferas de atuação.

Nesta concepção participativa, Maurício Wladman identificar três esferas de atuação conjunta que são indispensáveis para qualquer ação efetiva de conservação da natureza e de objetivação da cidadania ambiental. A primeira refere-se à administração pública, exercida nos níveis federal, estadual e o municipal. A segunda diz respeito à sociedade, que conta com

${ }^{15}$ BOBBIO, Norberto. A Era dos Direitos. Trad. Carlos Nelson Coutinho. Rio de Janeiro: Campus, 1992, p. 24. 
uma grande diversidade de interlocutores. Na esfera da sociedade, tem-se a atuação das escolas, das comunidades de bairros, das igrejas, dos sindicatos, dos movimentos urbanos e rurais, das universidades, bem como das empresas, que podem ser de capital privado e ter uma estratégia de atuação de interesse público, nessa incluindo as questões ambientais. A terceira esfera materializa-se em âmbito individual, com o cidadão atuando no espaço da sua casa, do seu bairro, do seu local de emprego e assim por diante ${ }^{16}$.

Como se pode perceber, as esferas da sociedade possíveis de articulação entre si para o desenvolvimento de projetos na área ambiental estão listadas em três distintas instâncias: o poder público, os entes não governamentais e os próprios indivíduos.

Leva-se em consideração que cada esfera deve atuar em conformidade com sua capacidade para a efetivação da proteção jurídica da água potável e, ainda, para a concretização do direito de acesso a esse bem elementar a todas as formas de vida no Planeta.

\section{CONCLUSÃO}

6.1 O Direito brasileiro oferece ampla proteção à água potável. Tanto a Constituição Federal quanto as leis infraconstitucionais revelam, de diversas formas, a existência de uma verdadeira teia normativa a proteger a água potável.

6.2 Embora o Brasil tenha uma legislação avançada para proteger a água potável, nota-se que isso por si só não basta. Torna-se necessário apostar na educação ambiental. As pessoas precisam assimilar a necessidade de proteger a água potável não porque a lei assim o estabelece, mas pela importância este bem essencial para a subsistência da vida humana.

${ }^{16}$ WLADMAN, Maurício apud PINSKY, Jaime; PINSKY, Carla Bassanezi (Org.) História da Cidadania. São Paulo: Contexto. 2003, p. 555. 
6.3 A existência, em cada pessoa, de uma conscientização ambiental é de relevante importância. Deve-se gerar em cada indivíduo a consciência de que cada um precisa fazer a sua parte.

6.4 A atitude ambiental deve existir por parte do Estado, da sociedade e de cada indivíduo. Este pode atuar em caráter pessoal, mas também por meio de ONG's, empresas privadas, associações, imprensa e igrejas. Tal pluralidade de atores deve atuar na preservação da água potável. Todos têm algo a fazer.

\section{REFERÊNCIAS}

ANA, Conselho Nacional de Desenvolvimento Científico e Tecnológico. Educação Ambiental e Gestão dos Recursos Hídricos. UEM. 2008.

BOBBIO, Norberto. A Era dos Direitos. Trad. Carlos Nelson Coutinho. Rio de Janeiro: Campus, 1992.

BRASIL. Ministério do Meio Ambiente. Programa Nacional da Educação Ambiental. 3 ed. 2005.

COMMETTI, F.D. et.al. O desenvolvimento do direito das águas como um ramo autônomo da ciência jurídica brasileiro. Revista de Direito Ambiental. 2008.

DAHL, Arthur Lyon. O princípio ecológico. Ecologia e economia em simbiose. Lisboa: Instituto Piaget. 1996.

DIAS, Genebaldo Freire. Educação ambiental: princípios e práticas. 8 ed, São Paulo: Gaia.

FACHIN, Zulmar. Curso de Direito Constitucional. 3. ed. São Paulo: Método, 2008.

FIORILLO,Celso Antonio Pacheco. Curso de direito ambiental brasileiro. São Paulo: Saraiva, 2009.

FREIRE, Paulo. Pedagogia do oprimido. São Paulo: Paz e Terra, 1985. p. 48.

LEFF, Enrique. Saber ambiental: sustentabilidade, racionalidade, complexidade, poder. trad. Lúcia Mathilde Endlich Orth. Petrópolis, Rio de Janeiro: Vozes, 2001.

OST, François. A natureza á margem da lei: a ecologia à prova do Direito. Lisboa: Instituto Piaget, 1995.

PINSKY, Jaime; PINSKY, Carla Bassanezi (Org.). História da Cidadania. São Paulo: Contexto. 2003. 


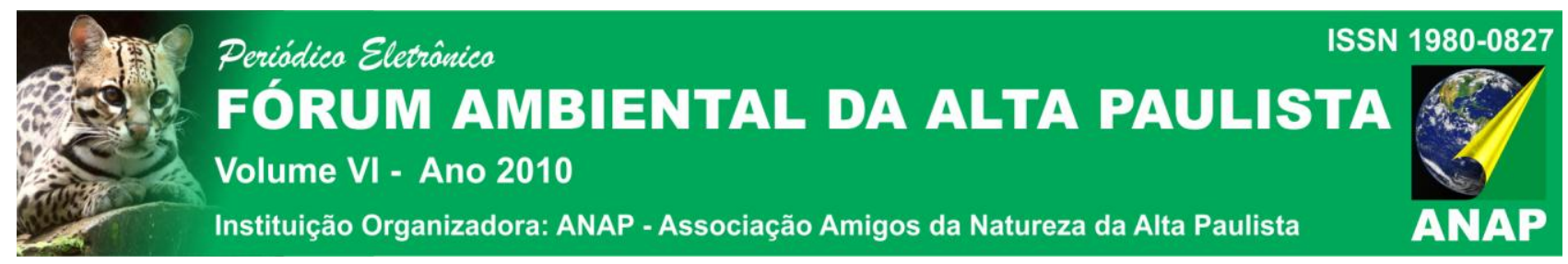

ZENNI, Alessandro Severino V. Direito e poder na filosofia pós-moderna. Revista Jurídica Cesumar, v. 5, n. 1, 2005. 